\title{
The Long-term Clinical Efficacy of Biofeedback Therapy for Patients With Constipation or Fecal Incontinence
}

\author{
Byoung Hwan Lee, $M D^{1}$, Nayoung Kim, $M D^{1 *}$, Sung-Bum Kang, $M D^{2}$, So Yeon Kim, $M D^{3}$, Kyoung-Ho Lee, $M D^{4}$, \\ Bo Youn Im, MA', Jung Hee Jee, $M A^{1}$, Jane C. Oh, MD', Young Soo Park, MD', and Dong Ho Lee, MD' \\ Departments of ${ }^{1}$ Internal Medicine, ${ }^{2}$ Surgery, and ${ }^{3}$ Radiology, Seoul National University Bundang Hospital, Seongnam, Gyeonggi-do, \\ Korea, ${ }^{4}$ Yonsei Plus Clinic, Seongnam, Gyeonggi-do, Korea
}

\section{Background/Aims}

There has been a controversy regarding the usefulness of biofeedback therapy for functional constipation or fecal incontinence. This study was performed to investigate the long-term clinical efficacy of biofeedback therapy.

\section{Methods}

Sixty-four patients with constipation or fecal incontinence received biofeedback therapy for 4 weeks. Symptom improvements were evaluated immediately after the completion of biofeedback therapy and during the follow-up period of about 12 to 64 months.

\section{Results}

Twenty-five patients in the constipation group [mean age of 52.1 years, 16 men (64.0\%)] received 6.2 sessions of biofeedback therapy. Improvement of constipation after the completion of biofeedback therapy was as follows: major response (or improvement) in 3 patients (12.0\%), fair in $6(24.0 \%)$, minor in $11(44.0 \%)$ and none in $5(20.0 \%)$. Among 9 patients who showed major or fair improvement, 8 patients (88.9\%) maintained the symptom improvement through the long term follow-up periods. Thirty-nine patients in the fecal incontinence group [59.7 years old, 15 men (38.5\%)] received 6.8 sessions of biofeedback therapy. Improvement of incontinence after the completion of biofeedback therapy was as follows: major improvement in 6 patients (15.4\%), fair in $14(35.9 \%)$, minor in $14(35.9 \%)$, and none in $5(12.8 \%)$. All 11 patients with major or fair improvement maintained the symptom improvement to the end of follow-up periods.

\section{Conclusions}

Symptom improvements after biofeedback therapy were disappointing in both the constipation and incontinence group. However, when the symptom improvements were classified as major or fair, the improvements continued for at least a year. (J Neurogastroenterol Motil 2010;16:177-185)

\section{Key Words}

Biofeedback, Therapy, Constipation, Fecal incontinence

Received: November 11th, 2009 Accepted: January 8th, 2010

(c) This is an Open Access article distributed under the terms of the Creative Commons Attribution Non-Commercial License (http://creativecommons. org/licenses/by-nc/3.0) which permits unrestricted non-commercial use, distribution, and reproduction in any medium, provided the original work is properly cited.

*Correspondence: Nayoung Kim, MD

Department of Internal Medicine, Seoul National University Bundang Hospital, 300 Gumi-dong, Bundang-gu, Seongnam, Gyeonggi-do 463-707, Korea

Tel: +82-31-787-7008, Fax: +82-31-787-4051, E-mail: nayoungkim49@empal.com

Financial support: None.

Conflicts of interest: None. 


\section{Introduction}

Constipation and fecal incontinence are common disorders in gastrointestinal area. These disorders are rarely life threatening, but could interfere with the quality of life and on individuals' self-image. Biofeedback therapy has been introduced as a method to treat these functional gastrointestinal disorders, especially for functional fecal incontinence and constipation by pelvic dyssynergia. This treatment modality has been reported to be effective, ${ }^{1-5}$ although there have been arguments over the studies on biofeedback therapy which were sometimes not controlled and had methodological problems.

Constipation is a common disorder with a prevalence of 2-27\% in adults. ${ }^{6,7}$ Most of these patients could be treated with conservative treatments such as high fiber diet and/or laxatives. However patients with severe constipation who do not respond to medications seek for further medical care. Biofeedback therapy has been effective for constipation by pelvic floor dyssynergia with the success rates of 60 to $80 \%{ }^{8,9}$ The biofeedback therapy is usually not effective for slow transit constipation. However, in slow transit constipation with pelvic floor dyssynergia, so-called mixed-type functional constipation, it has been effective as it is in normal transit constipation. ${ }^{10}$ Some investigators insisted biofeedback therapy to show clinical benefits even with slow transit constipation. ${ }^{11,12}$ In a recent controlled long-term follow-up study, the clinical benefits of biofeedback therapy in patients with pelvic floor dyssynergia were maintained for a long time. ${ }^{8-10,13}$

Fecal incontinence could be defined as an involuntary passage of fecal materials after at least 4 years of age. ${ }^{14}$ The prevalence of fecal incontinence is 2 to $17 \%$ and has been reported to increase among women, aged, and disabled. ${ }^{15}$ Although fecal incontinence is not a life threatening disorder, it could lead to various social and psychological problems. Choosing treatment strategy is based on the specific cause of fecal incontinence. When constipation occurs by a trauma to the anal sphincters during an obstetric procedure, or a surgical procedure, surgical modality is the first choice of treatment. The surgical treatment is shown to be highly effective in the short-term follow-up studies, whereas the results of long-term follow-up were questionable. ${ }^{16-18}$ When conservative treatment fails or when surgical correction is not amenable, other therapeutic modalities are needed. Biofeedback therapy is a non-invasive and easily feasible option which has been used for fecal incontinence over several decades. Numerous published studies support it as the first choice of treatment for fe- cal incontinence. ${ }^{19,20}$ These studies have reported a success rate of about $70 \%$ (between 40 to $100 \%$ ). ${ }^{1,21}$ However, in a recently randomized-controlled study, biofeedback therapy was not more helpful than supportive cares, such as life-style modification, drug treatment, or emotional support. ${ }^{22}$ Furthermore, instrumental feedback as well as non-instrumental feedback such as digital guidance could not prove any additional benefit of biofeedback therapy in a randomized-controlled trial. ${ }^{23} \mathrm{~A}$ well-designed controlled study is needed to clarify the efficacy of biofeedback therapy in patients with fecal incontinence.

The aim of this study was to evaluate both the short-term and long-term efficacy of biofeedback therapy, and to identify the predicting variables associated with success of the treatment in a single center in South Korea.

\section{Materials and Methods}

\section{Subjects}

Sixty-four patients with constipation or incontinence were consecutively enrolled in Seoul National University Bundang Hospital from June 2003 to January 2008. Twenty-four patients had constipation and 39 had fecal incontinence. Patients who completed less than 4 biofeedback sessions were excluded from the analysis.

\section{Methods}

Detailed medical history was taken to evaluate the duration of symptoms including any previous operation or trauma history. Before the biofeedback therapy, the physiological parameters were evaluated by anorectal manometry, balloon expulsion test and colonic transit testing. For the patients with fecal incontinence, transanal ultrasonography was performed to assess pathophysiologic status of the anal sphincter.

\section{1) Anorectal manometry with balloon expulsion test}

Before anorectal manometric evaluation, bowel preparation was performed by 2 pills of dulcorax suppository. Anorectal function testing was performed in the left-lateral position with the hips flexed to $90^{\circ}$. Anorectal manometry was performed using the water-perfusion technique with an 8-channel Micro Tip catheter (Medtronic) connected to a perfusion pump in the left-lateral position. The physiological parameters included the anal canal resting pressure, squeezing pressure, compliance, defecation index, resting and squeezing vectogram, and rectoanal inhibitory reflex. Rectal sensation was assessed by the inflation of a latex bal- 
loon with an air flow of $1 \mathrm{~mL}$ per second, and the threshold volumes for the first minimal sensation, desire to defecate, urge, and maximal tolerance were determined. The balloon expulsion test was carried out with $50 \mathrm{~mL}$ water filled balloon in the following order: the catheter was lubricated and inserted to the rectum, and then the balloon was filled with a $50 \mathrm{~mL}$ of water at room temperature. The patients were instructed to sit on a commode chair in a usual defecation position and to pass out the balloon. After waiting for 5 minutes, patients who could not pass the balloon across the anal canal were considered to have failed the balloon expulsion test.

\section{2) Colon transit time}

The colon transit time was measured using radio-opaque markers (Kolomark ${ }^{\mathrm{TM}}$, M.I.Tech., Pyongtaik, Korea). The subjects ingested one capsule containing 20 radio-opaque markers in the morning at 24-hour intervals for three consecutive days; 2 simple abdominal radiographs in the supine position were obtained on day 4 and day 7. Localization of the radio-opaque markers was determined by identifying the relations to landmarks of bony structure. ${ }^{24}$ That is, the markers located to the right side of the vertebral spinous processes above a line from the fifth vertebra to the right pelvic outlet were assigned to the right colon, the markers to the left of the vertebral spinous processes and above an imaginary line from the fifth lumbar vertebra to the anterior superior iliac crest were assigned to the left colon, and the markers inferior to a line from the pelvic brim on the right and the superior iliac crest on the left were considered to locate in the recto-sigmoid colon and rectum. The markers were counted by one experienced gastrointestinal radiologist (K.L.) and total and segmental colon transit times were calculated as 1.2 times the sum of the markers on the entire or a segment of colon. ${ }^{25,26}$

\section{3) Transanal ultrasound}

Twenty-two patients were evaluated with a transducer, which was protected by a rigid plastic anal cone, encased in a disposable condom, and inserted with the aid of lubricant. This examination was carried out in the left-lateral position, without anorectal preparation. An endosonic $360^{\circ}$ axial transducer was used to identify the anal cushion, as well as the internal and external anal sphincter (IAS and EAS, respectively). The IAS was defined as a homogenous, hypoechoic circular band that followed the mucosa and submucosa of the anal canal. Sphincter integrity was also determined by slow motion of the probe through the canal. The anal cushion and IAS thickness were determined in the middle anal canal in the ventral, dorsal, left and right lateral sphincter directions, as shown by the electronic cursor on the monitor. Patients with defect on the IAS or EAS were defined as having pathology.

\section{Biofeedback therapy and clinical assessment}

Biofeedback therapy was carried using the surface electromyography (EMG) method using a visual biofeedback system (Orion, Platinum, SRS Medical Systems, Inc., Redmond, WA, USA) and perianal sensor (Perry, Elan, SRS medical Systems, Redmond, WA, USA). Electrodes were attached to the lower abdomen and acryl plug was inserted into the anal canal. The patient watched a computer monitor displaying amplified, filtered EMG activity. The visual feedback was provided by observing changes in pressure activity on the computer monitor. Biofeedback therapy was planned for total of 10 sessions with 3 sessions per week during the first 2 weeks and 4 sessions during the last week. Sixty-minute biofeedback training session was performed at first and 30-minute session was performed from the second session. Each biofeedback training session was performed while the patient covered with a sheet and sitting on a chair to simulate defecation postures. In the biofeedback session for constipation, the patient was instructed to relax, squeeze, or strain gently for a series of 10-second trials. The therapist explained the appropriate EMG feature and therapeutic target. In the biofeedback session for fecal incontinence, the patient was instructed to squeeze and relax the anal sphincters repeatedly along with observing changes in pressure activity on a monitor screen. All patients were trained to perform pelvic exercise, modulate the habits of defecation, and modify the diet by verbal or video instructions during biofeedback sessions. The short-term clinical efficacy was measured immediately after the completion of biofeedback therapy and long-term efficacy was assessed according to the final telephone interview. The symptom responses categorized into 4 types are as follows: major improvement (more than $80 \%$ of symptom resolution), fair improvement (symptoms remained less than 50\%), mild improvement (symptoms remained for more than 50\%), and none (unresponsive to the biofeedback therapy). Then, the statistical analysis was performed by 2 groups: responder with fair or major subgroup and non-responder with none or mild subgroup.

\section{Statistical methods}

All data are reported as means \pm standard deviation. Chi-square and Mann-Whitney $U$ tests were used according to categorical or numeric data. A general linear model was used to compare the differences of anorectal function parameters between 2 examinations performed before and after biofeedback therapy. 
A p-value of less than 0.05 was considered statistically significant. Data were analyzed using the SPSS statistical software package (SPSS 15.0 for Windows, SPSS Inc., Chicago, IL, USA).

\section{Results}

\section{Characteristics of patients}

Total of 64 patients were enrolled; 25 patients had constipation $(39.1 \%)$ and 39 patients had fecal incontinence (60.9\%) (Table 1). The mean age was $52.1 \pm 18.6$ years in the constipation group and $59.7 \pm 16.7$ years in the fecal incontinence group. There were more males (64.0\%) than females $(36.0 \%)$ in the constipation group and more females $(61.5 \%)$ than males $(38.5 \%)$ in the fecal incontinence group $(\mathrm{p}=0.046)$. The bowel movement frequency was $2.5 \pm 1.8$ per week in the constipation group and $4.8 \pm 2.1$ per day in the fecal incontinence group (Table 1).

\section{Clinical efficacy of biofeedback therapy}

The mean follow-up period was $49.6 \pm 12.0$ months in the constipation group and $34.5 \pm 13.8$ months in the incontinence group, respectively. Improvement of constipation after completion of biofeedback therapy was noted by the following order: major improvement in 3 patients (12\%), fair in 6 (24\%), minor in $11(44 \%)$, and none in 5 (20\%). Among 9 patients who showed major or fair improvements (responder group), 8 patients (88.9\%) maintained the symptom improvements through the long-term follow-up periods. Among 39 incontinence patients, improvements of incontinence after completion of biofeedback therapy are as follows: major in 6 patients $(15.4 \%)$, fair in 14 (35.9\%), minor in 14 (35.9\%), and none in 5 (12.8\%). Among 11 patients who showed major or fair improvements (responder

Table 1. Baseline Characteristics of the Patients Before Biofeedback Therapy

\begin{tabular}{lcc}
\hline & $\begin{array}{c}\text { Constipation } \\
(\mathrm{n}=25)\end{array}$ & $\begin{array}{c}\text { Incontinence } \\
(\mathrm{n}=39)\end{array}$ \\
\hline Age (yr, mean $\pm \mathrm{SD})$ & $52.1 \pm 18.6$ & $59.7 \pm 16.7$ \\
Gender & & \\
$\quad$ Male $(\%)$ & $16(64)$ & $15(38.5)$ \\
$\quad$ Female $(\%)$ & $9(36)$ & $24(61.5)$ \\
Bowel frequency & $2.5 \pm 1.8 / \mathrm{wk}$ & $4.8 \pm 2.1$ day \\
Symptom duration & $166.4 \pm 160.3$ & $39.3 \pm 58.3$ \\
(mo) & & \\
Follow-up (mo) & $49.6 \pm 12.0$ & $34.5 \pm 13.8$ \\
\hline
\end{tabular}

group), all maintained the symptom improvements through the long-term follow-up periods.

\section{Biofeedback therapy sessions}

The average number of sessions for biofeedback therapy was 6.2 times in the constipation group and 6.8 times in the incontinence group. No significant difference was observed among the responder group in regard to the frequency of biofeedback sessions in both the constipation and incontinence patients.

\section{Anorectal physiological parameters}

Analysis was performed between the responder and non-responder group in either constipation or incontinence group. In the constipation group, no significant differences were found between the responder and non-responder group at baseline with regard to demographic variables such as age, symptom duration, and bowel frequency (Table 2). However, female responded more fairly to biofeedback therapy than male $(p=0.031)$ (Table 2 ). Also there were no significant differences between the responder and non-responder group with regard to the physiologic parameters such as resting pressure and squeezing pressure, although the defecation index was lower in the non-responder group ( $\mathrm{p}=0.041)$ (Table 3$)$. There were no differences in the minimal volume, urgent volume and critical volume in measuring the rectal sensory threshold, while the desire to defecate volume was smaller in the responder group. No differences in colon transit time and balloon expulsion test before biofeedback therapy

Table 2. Characteristics of Patients With Constipation at the Initial Enrollment and Comparison Based on the Response to Biofeedback Therapy

\begin{tabular}{lccc}
\hline & Responder $^{\mathrm{a}}$ & Non-responder $^{\mathrm{b}}$ & $\mathrm{p}$-value \\
\hline $\begin{array}{l}\text { Number (\%) } \\
\begin{array}{l}\text { Gender } \\
\text { (male/female) }\end{array}\end{array}$ & $9(36)$ & $16(64)$ & \\
Age (yr) & $58.8 \pm 7.9$ & $48.3 \pm 21.8$ & 0.552 \\
$\begin{array}{l}\text { Bowel frequency } \\
(/ \mathrm{wk})^{\mathrm{c}}\end{array}$ & $2.3 \pm 1.7$ & $2.6 \pm 1.9$ & 0.740 \\
$\begin{array}{l}\text { Symptom duration } \\
\text { (mo) }\end{array}$ & $240.4 \pm 212.6$ & $126.9 \pm 113.9$ & 0.428 \\
$\begin{array}{l}\text { Biofeedback therapy } \\
\text { (sessions) }\end{array}$ & $7.2 \pm 2.8$ & $6.6 \pm 2.9$ & 0.527 \\
\hline
\end{tabular}

${ }^{a}$ Major improvement (more than $80 \%$ symptom resolution) or fair improvement (symptoms less than 50\%), ${ }^{\text {b }}$ Mild improvement (symptoms remained more than $50 \%$ ) or none (unresponsive to the biofeedback therapy), ${ }^{\mathrm{c}}$ Frequency of defecation during 1 week.

Bold style indicates statistical significance. 
were noted (Table 3 ).

In the fecal incontinence group, there were no significant differences between the responder and non-responder group with regard to the physiological parameters; with the exception on the squeezing pressure before biofeedback therapy (Table 4). The responder group showed higher squeezing pressure than the non-responder group $(\mathrm{p}=0.027)$.

Follow-up anorectal manometry test was performed in 3 patients of the constipation group and 13 patients of the incontinence

Table 3. Physiological Parameters of the Patients With Constipation at the Initial Enrollment and Comparison Based on the Response to Biofeedback Therapy

\begin{tabular}{lccc}
\hline & $\begin{array}{c}\text { Responder }^{\mathrm{a}} \\
(\mathrm{n}=9)\end{array}$ & $\begin{array}{c}\text { Non-responder } \\
(\mathrm{n}=16)\end{array}$ & p-value \\
\hline $\begin{array}{l}\text { Anorectal manometry findings } \\
\text { Resting pressure } \\
\text { (mmHg) }\end{array}$ & $52.2 \pm 30.2$ & $48.6 \pm 13.8$ & 0.789 \\
$\begin{array}{l}\text { Squeezing pressure } \\
\text { (mmHg) }\end{array}$ & $137.6 \pm 61.5$ & $127.2 \pm 55.3$ & 0.640 \\
$\begin{array}{l}\text { Defecation index } \\
\text { Minimal volume }\end{array}$ & $2.86 \pm 3.46$ & $1.03 \pm 0.81$ & $\mathbf{0 . 0 4 1}$ \\
$\begin{array}{l}\text { (mL) } \\
\text { Desire to defecate }\end{array}$ & $71.1 \pm 10.5$ & $88.3 \pm 18.5$ & $\mathbf{0 . 0 1 9}$ \\
$\quad \begin{array}{l}\text { volume (mL) } \\
\text { Urgent volume } \\
\text { (mL) }\end{array}$ & $127.1 \pm 19.8$ & $150.0 \pm 49.3$ & 0.402 \\
$\begin{array}{l}\text { Critical volume } \\
\text { (mL) }\end{array}$ & $162.2 \pm 23.3$ & $205.0 \pm 89.0$ & 0.423 \\
$\begin{array}{l}\text { Colon transit time } \\
\text { (hr) }\end{array}$ & $61.3 \pm 49.9$ & $62.2 \pm 38.0$ & 0.910 \\
$\begin{array}{l}\text { Balloon expulsion test } \\
\text { (success/failure) }\end{array}$ & $7 / 2$ & $10 / 3$ & 0.962 \\
\hline
\end{tabular}

${ }^{a}$ Major improvement (more than $80 \%$ symptom resolution) or fair improvement (symptoms less than 50\%), ${ }^{\mathrm{b}}$ Mild improvement (symptoms remained more than $50 \%$ ) or none (unresponsive to the biofeedback therapy), ${ }^{c}$ Rectal pressure during straining/anal residual pressure during straining.

Bold style indicates statistical significance. group after completion of biofeedback therapy. Adequate analysis for the physiological parameters before and after biofeedback therapy was not able in the constipation group due to the small sample size. In the incontinence group, the squeezing pressure increased significantly after biofeedback therapy in the responder group as opposed to the non-responder group. There were no significant differences in the resting pressure and minimal sensory volume before and after biofeedback therapy (Table 5).

\section{Transanal ultrasound}

For the incontinence group, the status of anal sphincters was

Table 4. Characteristics and Physiological Parameters of Patients With Fecal Incontinence at the Initial Enrollment and Comparison Based on the Response to Biofeedback Therapy

\begin{tabular}{|c|c|c|c|}
\hline & $\begin{array}{c}\text { Responder }^{\mathrm{a}} \\
(\mathrm{n}=20)\end{array}$ & $\begin{array}{c}\text { Non-responder }{ }^{\mathrm{b}} \\
\quad(\mathrm{n}=19)\end{array}$ & $\mathrm{p}$-value \\
\hline Number (\%) & $20(51.3)$ & $19(48.7)$ & \\
\hline $\begin{array}{l}\text { Gender } \\
\text { (male/female) }\end{array}$ & $6 / 14$ & $9 / 10$ & 0.265 \\
\hline Age (yr) & $62.0 \pm 15.5$ & $57.1 \pm 18.1$ & 0.412 \\
\hline $\begin{array}{l}\text { Bowel frequency } \\
\text { (/day) }\end{array}$ & $5.1 \pm 2.1$ & $4.4 \pm 2.1$ & 0.290 \\
\hline $\begin{array}{l}\text { Symptom duration } \\
(\mathrm{mo})\end{array}$ & $31.6 \pm 50.2$ & $45.3 \pm 65.1$ & 0.365 \\
\hline $\begin{array}{l}\text { Biofeedback therapy } \\
\text { (sessions) }\end{array}$ & $6.5 \pm 2.9$ & $5.7 \pm 2.6$ & 0.579 \\
\hline \multicolumn{4}{|l|}{ Anorectal manometry } \\
\hline $\begin{array}{l}\text { Resting pressure } \\
(\mathrm{mmHg})\end{array}$ & $27.6 \pm 14.3$ & $24.2 \pm 15.1$ & 0.366 \\
\hline $\begin{array}{l}\text { Squeezing pressure } \\
(\mathrm{mmHg})\end{array}$ & $125.4 \pm 48.9$ & $91.2 \pm 43.7$ & 0.027 \\
\hline $\begin{array}{l}\text { Minimal sensory } \\
\text { volume }(\mathrm{mL})\end{array}$ & $30.5 \pm 13.9$ & $34.1 \pm 20.9$ & 0.749 \\
\hline
\end{tabular}

${ }^{a}$ Major improvement (more than $80 \%$ symptom resolution) or fair improvement (symptoms less than $50 \%$ ), ${ }^{\text {b }}$ Mild improvement (symptoms remained more than $50 \%$ ) or none (unresponsive to the biofeedback therapy).

Bold style indicates statistical significance.

Table 5. Changes of Manometric Parameters Before and After Biofeedback Therapy in Patients With Fecal Incontinence

\begin{tabular}{llcrl}
\hline & & Before biofeedback & After biofeedback & p-value \\
\hline Resting pressure $(\mathrm{mmHg})$ & Responder $\quad(\mathrm{n}=7)$ & $32.7 \pm 14.4$ & $22.8 \pm 15.0$ & 0.171 \\
& Non-responder $(\mathrm{n}=6)$ & $19.6 \pm 8.5$ & $18.1 \pm 16.2$ & \\
Squeezing pressure $(\mathrm{mmHg})$ & Responder $\quad(\mathrm{n}=7)$ & $118.2 \pm 23.8$ & $142.7 \pm 35.7$ & $\mathbf{0 . 0 1 9}$ \\
& Non-responder $(\mathrm{n}=6)$ & $90.8 \pm 37.1$ & $79.8 \pm 38.2$ & \\
Minimal volume $(\mathrm{mL})$ & Responder $\quad(\mathrm{n}=7)$ & $25.7 \pm 9.7$ & $33.3 \pm 16.3$ & 0.235 \\
& Non-responder $(\mathrm{n}=6)$ & $25.0 \pm 9.2$ & $34.2 \pm 15.1$ & \\
\hline
\end{tabular}

Bold style indicates statistical significance. 
evaluated by transanal ultrasound in 27 patients. Sixteen patients (59.3\%) had normal anal sphincters while 11 patients (40.7\%) had anal sphincter defect or thinning. Among 16 patients with normal anal sphincters, 10 patients $(62.5 \%)$ responded to biofeedback therapy, whereas 4 (36.4\%) out of 11 patients with anal sphincter defect or thinning responded to biofeedback therapy. However, this result was not statistically significant $(\mathrm{p}=0.182)$.

\section{Discussion}

Biofeedback therapy has been reported to be an effective treatment for functional anorectal disorders such as functional constipation and functional fecal incontinence over the past few decades. ${ }^{2,27}$ Biofeedback therapy has been accepted as the treatment of choice for pelvic floor dyssyndergia and fecal incontinence due to its clinical efficacy. However, there continues to be controversies regarding its efficacy. First, most of the clinical findings were found to be based on the uncontrolled studies. In addition, many of the studies had methodological limitations, such as the differences in the criteria used to define successful outcome, the heterogeneity of the participants studied, and the different variables considered during the assessments. Furthermore, some studies did not show biofeedback therapy to be more effective than conservative treatments especially in patients with fecal incontinence ${ }^{22,23}$ and childhood functional constipation. ${ }^{28}$ However, the more important issue would be about the effects of biofeedback therapy to be maintained or not. As biofeedback therapy is a relatively inexpensive and non-invasive modality, it could be considered as the first-line therapy in patients with refractory anorectal disorders when its efficacy is predicted to be maintained for a long time interval.

Constipation could be classified into normal-transit constipation, pelvic floor dyssynergia, slow-transit constipation, and the mixed type according to the results of physiological testing. ${ }^{29}$ In a large epidemiological study, normal transit constipation was the most common subtype (59\%), followed by pelvic floor dyssyndergia (25\%), slow transit constipation (13\%), and the mixed type $(3 \%) .{ }^{30}$ Several treatment modalities have been adopted for constipation such as life-style modification, medications, biofeedback therapy, injection of botulinum toxin, ${ }^{31}$ sacral nerve stimulation, ${ }^{32}$ anorectal electrical stimulation, ${ }^{33}$ and surgical treatment. ${ }^{34}$ Biofeedback therapy has been studied mainly in patients with pelvic floor dyssynergia. This disorder, which has also been called as anismus, an outlet obstruction or spastic pelvic floor syndrome, is a type of constipation characterized by a failure to relax the puborectalis muscle, the external and internal anal sphincter muscle during the straining for defecation. In recent controlled studies, Chiarioni et al. ${ }^{8,10}$ reported biofeedback as an effective treatment for pelvic floor dyssynergia superior to laxatives with the improvement to be maintained for a long-term follow interval, while the effect was not found in cases of slow transit constipation. Biofeedback therapy was more effective than conservative treatments or sham feedback treatment in patients with pelvic floor dyssyndergia. ${ }^{13}$ Altogether these studies suggest biofeedback therapy to be highly effective for pelvic floor dyssynergia with the effects being long-lasting. Furthermore, some studies reported the effectiveness of biofeedback therapy for slow-transit constipation, ${ }^{11,12}$ which was shown by the improvement of cerebral cortex activity controlling colon motility. ${ }^{35,36}$ In the present study, we applied biofeedback therapy for refractory constipation patients regardless of the constipation type. The effect of biofeedback therapy was found in $36 \%$ of constipation patients with $88.9 \%$ of the responder group maintaining the symptom improvements for the long follow-up intervals. The lower outcome of biofeedback therapy just after the completion of biofeedback therapy may have originated from the broad category of participants including those with slow-transit constipation. Furthermore, defecation index, which is specific for pelvic floor dyssynergia, ${ }^{26}$ was significantly lower in the non-responder group. Again these results could be due to the broad indication of biofeedback therapy with the relatively old participants in our study. Several studies have evaluated the variables associated with successful outcome. ${ }^{8,10,37}$ Park et al. ${ }^{37}$ reported the defecation index and pelvic floor dyssynergia as factors influencing the response by multivariate analysis. Other investigators have suggested milder constipation, less frequent abdominal pain, digital facilitation, slow transit, and the defecation index to be associated with successful outcome. But not a common specific variable emerged when a critical review was performed. ${ }^{1}$ In our study, the rectal sensory parameters showed relatively lower pressures and volumes in the responder group and desire to defecate volume was also significantly lower in the responder group than in the non-responder group. In other words, the non-responder group showed higher minimal volume, desire to defecate volume, urgent volume, and critical volume than the responder group and the difference in desire to defecate volume was statistically significant. Furthermore, similar trend was observed in the follow-up anorectal manometry test after completion of biofeedback therapy. Urgent volume after biofeedback therapy was statistically higher in the non-responder group $(180 \mathrm{~mL}$ vs. $140 \mathrm{~mL}, \mathrm{p}$ 
$=0.031)$. Rectal hyposensitivity is associated not only with functional GI disorders but also with the response to biofeedback therapy, which is more effective in patients with relatively preserved anorectal physiology. Recently, rectal hyposensitivity has been considered as a causal factor for functional GI disorders and some authors are trying therapeutic modalities such as electrical stimulation. ${ }^{33,38}$ Chang et al. ${ }^{33}$ reported the efficacy of electrical stimulation to be comparable to biofeedback therapy in a subgroup of constipation, especially in those with impaired rectal sensation. The pathophysiological mechanisms of rectal hyposensitivity are not well-known, but some studies have shown the association with diminished rectal perception. ${ }^{39}$ There were no specific physiologic, anatomic, or demographic variable associated with successful outcome.

Fecal incontinence is defined as a recurrent uncontrolled passage of fecal material which presents with a social as well as a personal hygienic problem. ${ }^{40}$ The cause of fecal incontinence varies and includes abnormalities of intestinal motility, poor rectal compliance, impaired rectal sensation, or weakened pelvic floor muscles. ${ }^{2}$ In patients with muscle or nerve damage due to disease pathology, obstetric injuries, or rectal prolapse, treatment must be determined based on the cause. ${ }^{2}$ However, the fact that the pathophysiology and physiological dysfunction to coexist as synergistic factors may make biofeedback therapy a useful first-line therapy. A few studies showed biofeedback therapy to be selectively effective in patients who were initially considered for surgery. ${ }^{41,42}$ In our study, 11 patients were identified with anal sphincter injury by transanal ultrasound; 6 patients showed thinning of anal sphincter, 5 patient showed defect of anal sphincter. Out of 6 patients showing the thinning, 3 patients responded to biofeedback therapy and among 5 patients showing the defect, only one patient responded to biofeedback therapy. The generally low response rate of biofeedback therapy may lead to surgical modality, but patients who do not have severe damage could be considered as candidates for biofeedback therapy. Demographic features of fecal incontinence are more common in women than men and increase with age in adults, probably due to the pelvic changes and trauma associated with childbirth. ${ }^{43}$ Women have a better response than men, for reasons not yet determined. ${ }^{44}$ In our study, female patients $(24,61.5 \%)$ were more prevalent than male $(15,38.5 \%)$ in the incontinence group, but no statistical difference was noted with regard to the clinical efficacy. Although biofeedback therapy has been reported to be an effective treatment for fecal incontinence for over the past 30 years, the studies performed are lacking in adequately controlled data. ${ }^{1,2}$ Recent randomized, controlled, and blinded trials have not shown the superiority of biofeedback therapy compared to standard care supplemented by advice and education. ${ }^{22,45}$ In addition, non-instrumental feedback using simple digital insertion was equally as effective as instrumental biofeedback therapy. ${ }^{23}$ In spite of these limitations of biofeedback therapy, recent studies have concluded biofeedback-induced improvement to be maintained for a long time interval after treatment. ${ }^{21,22}$ There continues to be controversy on the use of biofeedback therapy for fecal incontinence, which may account for the reluctance in clinical use and the need for well-designed controlled studies to assess its efficacy. In our study, the clinical effect of biofeedback therapy was observed in 20 patients $(51.3 \%)$ among 39 participants. Similar to other recent data, all patients who responded to biofeedback therapy have maintained the improvement on the most recent follow-up by telephone interview in the present study. Again the low response rate in the present study may have been due to the broad range of participants including anal sphincter defects caused by surgical procedures. Variables which tend to negatively affect the clinical outcome were reported to be the underlying neurological impairment and the heterogeneity of study group, ${ }^{1}$ as in our data. No objective factors has been identified in a critical review of many studies to date. ${ }^{1}$ Some studies have shown the improvement of manometric parameters after biofeedback therapy. ${ }^{23,46}$ However, most of the data points to inconsistencies between subjective improvement and objective parameters such as manometric changes. ${ }^{47}$ In our study, a high anal squeezing pressure was an indicator for a good response $(p=0.027)$. In addition, the responder group showed increases in the anal squeezing pressure after biofeedback therapy ( $p=0.019)$. These results in the incontinence group suggest patients with mild anorectal pathophysiology to present with a good response to biofeedback therapy as in the constipation group. We could not find any other objective parameters than the anal squeezing pressure which correlated with the clinical efficacy evaluated by the anorectal manometry after completion of biofeedback therapy.

In our study, there are several methodological problems. First of all, we did not use the Rome II or Rome III criteria. Instead, biofeedback was performed in patients with either constipation or incontinence who did not respond to conservative medical therapy such as life-style modifications and medications. Second, the criteria for the evaluation of clinical efficacy were rather subjective. Successful outcome was defined depending on the patient's subjective report. Third, follow-up periods were variable. However, as biofeedback therapy has not been estab- 
lished as a standard therapy for constipation or incontinence and the response rate has been known to be inconsistent, it might be a valuable attempt to analyze the efficacy of biofeedback therapy in the crude patient group and share the experience of one institution.

In conclusion, biofeedback therapy in our study showed low successful outcome, but the clinical efficacy was maintained for a long time once the patients responded to the therapy. As patients with mild anorectal pathophysiology show good response to biofeedback therapy, it must be considered as the first therapeutic modality for functional anorectal disorders before they advance into more serious cases.

\section{References}

1. Heymen S, Jones KR, Ringel Y, Scarlett Y, Whitehead WE. Biofeedback treatment of fecal incontinence: a critical review. Dis Colon Rectum 2001;44:728-736.

2. Palsson OS, Heymen S, Whitehead WE. Biofeedback treatment for functional anorectal disorders: a comprehensive efficacy review. Appl Psychophysiol Biofeedback 2004;29:153-174.

3. Hibi M, Iwai N, Kimura O, Sasaki Y, Tsuda T. Results of biofeedback therapy for fecal incontinence in children with encopresis and following surgery for anorectal malformations. Dis Colon Rectum 2003;46(suppl 10):54-58.

4. Norton C. Fecal incontinence and biofeedback therapy. Gastroenterol Clin North Am 2008;37:587-604.

5. Rao SS. Dyssynergic defecation and biofeedback therapy. Gastroenterol Clin North Am 2008;37:569-586.

6. Sonnenberg A, Koch TR. Physician visits in the United States for constipation: 1958 to 1986. Dig Dis Sci 1989;34:606-611.

7. Stewart WF, Liberman JN, Sandler RS, et al. Epidemiology of constipation (EPOC) study in the United States: relation of clinical subtypes to sociodemographic features. Am J Gastroenterol 1999; 94:3530-3540.

8. Chiarioni G, Whitehead WE, Pezza V, Morelli A, Bassotti G. Biofeedback is superior to laxatives for normal transit constipation due to pelvic floor dyssynergia. Gastroenterology 2006;130:657-664.

9. Rao SS, Seaton K, Miller M, et al. Randomized controlled trial of biofeedback, sham feedback, and standard therapy for dyssynergic defecation. Clin Gastroenterol Hepatol 2007;5:331-338.

10. Chiarioni G, Salandini L, Whitehead WE. Biofeedback benefits only patients with outlet dysfunction, not patients with isolated slow transit constipation. Gastroenterology 2005;129:86-97.

11. Brown SR, Donati D, Seow-Choen F, Ho YH. Biofeedback avoids surgery in patients with slow-transit constipation: report of four cases. Dis Colon Rectum 2001;44:737-739.

12. Chiotakakou-Faliakou E, Kamm MA, Roy AJ, Storrie JB, Turner IC. Biofeedback provides long-term benefit for patients with intractable, slow and normal transit constipation. Gut 1998;42:517-521.

13. Heymen S, Scarlett Y, Jones K, Ringel Y, Drossman D, Whitehead WE. Randomized, controlled trial shows biofeedback to be superior to alternative treatments for patients with pelvic floor dyssynergia-type constipation. Dis Colon Rectum 2007;50:428-441.

14. Whitehead WE, Wald A, Diamant NE, Enck P, Pemberton JH, Rao SS. Functional disorders of the anus and rectum. Gut 1999;45:55-59.

15. Nelson RL. Epidemiology of fecal incontinence. Gastroenterology 2004;126(1 suppl 1):3-7.

16. Bravo Gutierrez A, Madoff RD, Lowry AC, Parker SC, Buie WD, Baxter NN. Long-term results of anterior sphincteroplasty. Dis Colon Rectum 2004;47:727-731.

17. Halverson AL, Hull TL. Long-term outcome of overlapping anal sphincter repair. Dis Colon Rectum 2002;45:345-348.

18. Madoff RD. Surgical treatment options for fecal incontinence. Gastroenterology 2004;126(1 suppl 1):S48-S54.

19. Chiarioni G, Ferri B, Morelli A, Iantorno G, Bassotti G. Bio-feedback treatment of fecal incontinence: where are we, and where are we going? World J Gastroenterol 2005;11:4771-4775.

20. Whitehead WE, Wald A, Norton NJ. Treatment options for fecal incontinence. Dis Colon Rectum 2001;44:131-142.

21. Norton C, Kamm MA. Anal sphincter biofeedback and pelvic floor exercises for faecal incontinence in adults - a systematic review. Aliment Pharmacol Ther 2001;15:1147-1154.

22. Norton C, Chelvanayagam S, Wilson-Barnett J, Redfern S, Kamm MA. Randomized controlled trial of biofeedback for fecal incontinence. Gastroenterology 2003;125:1320-1329.

23. Solomon MJ, Pager CK, Rex J, Roberts R, Manning J. Randomized, controlled trial of biofeedback with anal manometry, transanal ultrasound, or pelvic floor retraining with digital guidance alone in the treatment of mild to moderate fecal incontinence. Dis Colon Rectum 2003;46:703-710.

24. Arhan P, Devroede G, Jehannin B, et al. Segmental colonic transit time. Dis Colon Rectum 1981;24:625-629.

25. Jung HK, Kim DY, Moon IH. Effects of gender and menstrual cycle on colonic transit time in healthy subjects. Korean J Intern Med 2003;18:181-186.

26. Metcalf AM, Phillips SF, Zinsmeister AR, MacCarty RL, Beart RW, Wolff BG. Simplified assessment of segmental colonic transit. Gastroenterology 1987;92:40-47.

27. Jorge JM, Habr-Gama A, Wexner SD. Biofeedback therapy in the colon and rectal practice. Appl Psychophysiol Biofeedback 2003;28:47-61.

28. Sunic-Omejc M, Mihanovic M, Bilic A, et al. Efficiency of biofeedback therapy for chronic constipation in children. Coll Antropol 2002;26(suppl):93-101.

29. Lembo A, Camilleri M. Chronic constipation. N Engl J Med 2003;349:1360-1368.

30. Nyam DC, Pemberton JH, Ilstrup DM, Rath DM. Long-term results of surgery for chronic constipation. Dis Colon Rectum 1997;40:273-279.

31. Maria G, Cadeddu F, Brandara F, Marniga G, Brisinda G. Experience with type A botulinum toxin for treatment of outlet-type constipation. Am J Gastroenterol 2006;101:2570-2575.

32. Holzer B, Rosen HR, Novi G, et al. Sacral nerve stimulation in patients with severe constipation. Dis Colon Rectum 2008;51:524-529.

33. Chang HS, Myung SJ, Yang SK, et al. Effect of electrical stimulation in constipated patients with impaired rectal sensation. Int $\mathrm{J}$ 
Colorectal Dis 2003;18:433-438.

34. Sung IK. Classification and treatment of constipation. Korean J Gastroenterol 2008;51:4-10.

35. Emmanuel AV, Kamm MA. Response to a behavioural treatment, biofeedback, in constipated patients is associated with improved gut transit and autonomic innervation. Gut 2001;49:214-219.

36. Wiesel PH, Norton C, Roy AJ, Storrie JB, Bowers J, Kamm MA. Gut focused behavioural treatment (biofeedback) for constipation and faecal incontinence in multiple sclerosis. J Neurol Neurosurg Psychiatry 2000;69:240-243.

37. Park DH, Myung SJ, Yoon IJ, et al. Clinical factors associated with response to biofeedback therapy for patients with chronic constipation. Korean J Gastroenterol 2003;42:289-296.

38. Chang HS, Myung SJ, Yang SK, et al. Functional constipation with impaired rectal sensation improved by electrical stimulation therapy: report of a case. Dis Colon Rectum 2004;47:933-936.

39. Gladman MA, Aziz Q, Scott SM, Williams NS, Lunniss PJ. Rectal hyposensitivity: pathophysiological mechanisms. Neurogastroenterol Motil 2009;21:508-516.

40. Wald A. Clinical practice. Fecal incontinence in adults. N Engl J Med 2007;356:1648-1655.

41. Allgayer H, Dietrich CF, Rohde W, Koch GF, Tuschhoff T. Prospective comparison of short- and long-term effects of pelvic floor exercise/biofeedback training in patients with fecal incontinence after surgery plus irradiation versus surgery alone for colorectal cancer: clinical, functional and endoscopic/endosonographic findings. Scand J Gastroenterol 2005;40:1168-1175.

42. Fynes MM, Marshall K, Cassidy M, et al. A prospective, randomized study comparing the effect of augmented biofeedback with sensory biofeedback alone on fecal incontinence after obstetric trauma. Dis Colon Rectum 1999;42:753-758.

43. MacLennan AH, Taylor AW, Wilson DH, Wilson D. The prevalence of pelvic floor disorders and their relationship to gender, age, parity and mode of delivery. BJOG 2000;107:1460-1470.

44. Byrne CM, Smith SR, Solomon MJ, Young JM, Eyers AA, Young CJ. Long-term functional outcomes after laparoscopic and open rectopexy for the treatment of rectal prolapse. Dis Colon Rectum 2008;51:1597-1604.

45. Ilnyckyj A, Fachnie E, Tougas G. A randomized-controlled trial comparing an educational intervention alone vs education and biofeedback in the management of faecal incontinence in women. Neurogastroenterol Motil 2005;17:58-63.

46. Martinez-Puente Mdel C, Pascual-Montero JA, Garcia-Olmo D. Customized biofeedback therapy improves results in fecal incontinence. Int J Colorectal Dis 2004;19:210-214.

47. Terra MP, Deutekom M, Dobben AC, et al. Can the outcome of pelvic-floor rehabilitation in patients with fecal incontinence be predicted? Int J Colorectal Dis 2008;23:503-511. 